\title{
ICONICIDADE, GRAMÁTICA E TEXTO ${ }^{1}$
}

Vania. L. R. Dutra (UERJ)

Resumo: Pretende-se, com este trabalho, investigar a possibilidade de motivação icônica para a forma linguística. Buscam-se evidências que podem admitir a existência de uma iconicidade diagramática, ou seja, busca-se a comprovação de que "os arranjos estruturais refletem relações análogas existentes na estrutura semântica" (NEVES, 2007, p. 23) do texto que se constrói. Trabalhar-se-á com a noção de que as construções linguísticas que se disponibilizam para nós são determinadas pelos usos a que as sujeitamos, isto é, os sentidos que queremos construir auxiliam na configuração dos recursos linguísticos. Com base na LSF, analisaremos a variação funcional dos textos (gêneros), o modo como eles se diferenciam e as possíveis motivações para tais diferenças. Especificamente, verificaremos o modo como a linguagem funciona na construção dos textos (sequências textuais - se são argumentativas, descritivas, narrativas), o que determina grandemente os significados textuais. Conforme Halliday, "a natureza da língua está intimamente relacionada com as necessidades que the impomos, com as funções que deve servir." (1976, p. 141).

Palavras-chave: Iconicidade diagramática. Gramática. Texto.

Abstract: With this work, we intend to investigate the iconic motivation possibility to linguistic form. We try to show evidences that can consider the existence of diagramatic iconicity, that is, we aim to prove that structural constructions reflect analogous relations in semantic structures" (NEVES, 2007, p. 23) of the texts we construct. We will work with the notion that the linguistic constructions available for us are determinate for the uses we impose to them, that is, the senses we want to build help in the configuration of the linguistic issues. Based on SFL, we will study the texts functional variation (genres), the way they differ and the possible motivations for these differences. Specifically, we will verify the way language functions in texts building (textual sequencies -

1 Este texto é fruto de uma atualização de artigo publicado em SIMÕES, Darcilia; POLTRONIERI, Ana Lúcia; FREITAS, Maria Noêmi (Orgs.). A contribuição da semiótica no ensino e na pesquisa. Rio de Janeiro: Dialogarts Publicações, 2010. 
if they are argumentative, descriptive, narrative), what enormously determine textual senses. As Halliday, "language nature is strictly related to the necessities we impose, with the functions it should serve." (1976, p. 141).

Key words: Diagramatic iconicity. Grammar. Text.

\section{INTRODUÇÃO}

Sabemos hoje, os professores de Português, algo que nossos alunos já sabiam há muito e que motivava os tantos questionamentos sobre a aplicabilidade, na vida fora da escola, do que estudavam em nossas aulas: o trabalho que tem como objetivo e como finalidade a gramática não ensina a ler e a escrever.

As gramáticas classificam as palavras em substantivo, adjetivo, verbo, advérbio, conjunção, pronome, numeral, artigo e preposição. Os poetas classificam as palavras pela alma porque gostam de brincar com elas e para brincar com elas é preciso ter intimidade primeiro. (FALCÃO, 2013, p. 71)

Essa intimidade com a língua a que se refere a poeta só pode ser garantida por meio da proximidade com os textos, ou seja, por meio da leitura e da escrita em uma prática sistemática na escola. Não se nega aqui a importância da gramática, do conhecimento sobre as estruturas da língua que vêm sendo objeto de trabalho na escola ao longo se sua existência como instituição. Pelo contrário: nosso objetivo 
é reafirmar sua importância, mas sustentando que esses conhecimentos devem ser apresentados e discutidos de forma contextualizada e articulada, para que possam ser mobilizados pelos estudantes no momento da leitura e da escrita de textos, na escola e na vida.

Os documentos oficiais que parametrizam a Educação no País já vêm nos mostrando, há algum tempo, um caminho que nos aproxima desse objetivo. A Base Nacional Curricular Comum (BNCC) propõe um trabalho com o texto que favoreça o desenvolvimento de competências e habilidades. Para tanto, prioriza a entrada de gêneros textuais diferentes na escola e enfatiza a prática da leitura e da escrita como meio e como fim do trabalho desenvolvido.

Um trabalho com a língua que objetive a ampliação da competência comunicativa dos alunos precisa conceber a língua como um instrumento para a interação social e privilegiar sua funcionalidade. Essa concepção de língua levou-nos naturalmente a uma abordagem funcionalista para embasar os estudos que vimos desenvolvendo em relação ao ensino de Língua Portuguesa na Escola Básica.

Para os funcionalistas, a questão a ser investigada é como a comunicação é obtida por meio da língua, como os falantes se comunicam eficientemente. A língua, na visão funcionalista, 
não é um sistema autônomo, e a gramática é entendida em "referência a parâmetros como cognição e comunicação, processamento mental, interação social e cultura, mudança e variação, aquisição e evolução" (NEVES, 1997, p. 3).

A gramática assim considerada analisa a estrutura da língua em relação a toda a situação comunicativa - os interlocutores, os objetivos do evento da fala, o contexto discursivo - e estabelece relações entre o sistema linguístico, seus elementos e as funções que eles cumprem na comunicação. É a chamada "gramática funcional", cuja tarefa, conforme Beaugrande (apud NEVES, 1997, p. 3), é "fazer correlações ricas entre forma e significado dentro do contexto global do discurso".

Ao se admitir essa relação entre forma e função, entre gramática e significado, admite-se que a forma linguística pode, de fato, ter uma motivação icônica. É o que procuramos verificar com este trabalho: a possibilidade de motivação icônica para a forma linguística. Buscamos evidências que pudessem admitir a existência de uma iconicidade diagramática, ou seja, a comprovação de que "os arranjos estruturais refletem relações análogas existentes na estrutura semântica" (NEVES, 1997, p. 23) dos textos. É o que passamos a discutir com base na visão funcionalista 
da linguagem, principalmente a partir dos ensinamentos de Michael Halliday (1994) e na teoria da iconicidade verbal.

\section{VISÃO FUNCIONALISTA DA LINGUAGEM}

Consideramos aqui alguns aspectos distintivos entre a visão formalista e a visão funcionalista da linguagem. A primeira trata da estrutura sistemática das formas da língua, enquanto a segunda preocupa-se com a relação sistemática entre as formas e as funções na língua. Essas duas abordagens delineiam o que chamamos, respectivamente, "gramática formalmente orientada" e "gramática funcionalmente orientada". Entendemos, entretanto, que esses dois programas teóricos não são necessariamente excludentes, havendo entre eles um caráter de complementariedade (OLIVEIRA, 2004; PEZZATI, 2004). A nosso ver, o professor, embora possa e deva assumir uma concepção de língua para nortear o seu trabalho, não deve desconsiderar as contribuições que a coexistência de perspectivas teóricas diferentes e complementares pode trazer.

Segundo Halliday (1994), a diferença básica entre essas duas correntes dos estudos gramaticais baseia-se na oposição fundamental entre uma orientação primariamente sintagmática e uma orientação primariamente 
paradigmática. Assentada na primeira orientação, a gramática formalmente orientada interpreta a língua como uma lista de estruturas, entre as quais relações regulares podem ser estabelecidas secundariamente; enfatiza os traços universais das línguas e toma a sintaxe como base, organizando a língua em torno da frase. Assentada na segunda orientação, a gramática funcionalmente orientada entende a língua como uma rede de relações, com a atualização das estruturas funcionando como a realização dessas relações; evidencia as variações entre as línguas e toma a semântica como base, organizando a língua em torno do texto e do discurso.

Na base dessa diferenciação está o fato de os formalistas encararem a linguagem como fenômeno mental, estudando a língua como um sistema autônomo, enquanto os funcionalistas a veem como um fenômeno social, estudando-a em relação à função social que desempenha.

Para Bakhtin (2003), a natureza social da linguagem impõe que ela seja analisada com base em seu aspecto enunciativo-discursivo, isto é, na interação verbal e no enunciado. Contrário à visão tradicional, que trata a língua como sistema abstrato, ideal e fechado em si mesmo, o autor aponta a enunciação, produto das interações sociais, 
como a unidade de estudo da língua. Essa enunciação concretiza-se por meio de enunciados, que, como signos ideológicos, acompanham os atos de compreensão e interpretação nas interações.

Para o autor, falamos por meio de gêneros dentro de determinada esfera da atividade humana. Não atualizamos simplesmente um código linguístico, mas moldamos a nossa fala aos parâmetros de um gênero no interior de uma atividade. Não se pode pensar o gênero em si mesmo ou em seus aspectos formais somente. Suas funções sócio-verbais e ideológicas são imprescindíveis para sua constituição. Os gêneros são fenômenos complexos que envolvem, entre outros, aspectos linguísticos, discursivos, interacionais, sociais, pragmáticos, históricos.

Em nosso fazer diário, empregamos muitos gêneros de forma segura e adequada, embora teoricamente não tenhamos consciência de sua existência. Adquirimos esse conhecimento empírico sobre os gêneros assim como adquirimos a língua materna, nas trocas diárias de enunciações concretas, em todas as situações comunicativas com nossos interlocutores, quando as ouvimos/lemos e reproduzimos. Conhecer o funcionamento dos gêneros que usamos equivale, em relação à língua, a conhecer 
a organização de sua gramática. Tal conhecimento possibilita-nos extrair, de um e de outro - do gênero e da língua, que apreendemos em conjunto e que são, ambos, indispensáveis à compreensão mútua -, o melhor em termos de expressividade e comunicabilidade. Com base na Linguística Funcional, consideramos a variação funcional dos gêneros, o modo como eles se diferenciam e as possíveis motivações para tais diferenças.

De acordo com Halliday: "A linguagem é o que é por causa das funções que ela desenvolveu para exercer na vida das pessoas; é de se esperar que as estruturas linguísticas possam ser entendidas em termos funcionais" (1979, p. 4-5).

\section{ICONICIDADE DIAGRAMÁTICA}

Os estudos sobre iconicidade na língua e, portanto, na sua organização gramatical, têm chamado a atenção para uma possível motivação icônica, ou seja, para o reflexo, nos elementos estruturais dos textos, de relações existentes em sua estrutura semântica. Conforme Neves (1997), “a iconicidade é um princípio pelo qual se considera que existe uma relação não arbitrária entre forma e função, ou entre código e mensagem na linguagem humana.

A despeito da absoluta arbitrariedade apregoada pelos estruturalistas, as bases funcionalistas vêm fortalecendo passo 
a passo a existência de iconicidade nas gramáticas das línguas, demonstrando a existência de uma correlação um-a-um entre forma e interpretação semântico-pragmática pautada numa motivação funcional imanente aos aspectos estruturais observados. (cf. DECAT et al., 2001, p. 36)

Considerando-se que o texto escrito pode ser tido como um objeto visual, e que a leitura é um processo de semiose - de geração de sentidos -, o instrumental semiótico adquire grande relevância para a análise do signo-texto. Conforme Simões:

Do ponto de vista da análise verbal, a iconicidade pode ser observada não só no plano da estruturação gramatical, mas também num plano maior, mais abrangente, da trama textual. É observável: a seleção vocabular como representativa de usos e costumes diversos; a colocação dos termos nos enunciados como imagem das opções de enfoque ou das posições discursivas; a eleição do gênero e do tipo textual como indicador da relevância dos itens temáticos e lexicais contemplados no texto, etc. (2009, p. 77-78)

Aliando pressupostos teóricos da Semiótica Linguística de Peirce, da Gramática Sistêmico-Funcional de Halliday e da abordagem pragmático-textual de Adam, consideramos que os recursos linguísticos que entram na organização dos textos são verdadeiros signos e que, portanto, têm potencial icônico. 
Buscando evidenciar uma motivação icônica para a forma linguística na construção dos textos, analisamos a iconicidade diagramática - em sua plasticidade (diagramação) e função social (objetivos sociocomunicativos), e em sua estruturação linguística (aspectos discursivo-gramaticais). Os conceitos de gênero e de sequências textuais são então considerados numa perspectiva funcional, o que faz com que se possa trabalhar com eles de forma mais produtiva em sala de aula, avaliando as funções dos gêneros e os valores projetados sobre os signos que compõem as diversas sequências textuais.

\section{O TEXTO NA SALA DE AULA}

A perspectiva de trabalho com os textos com base nos pressupostos teóricos da Linguística Sistêmico Funcional e da Semiótica - no que essas abordagens podem contribuir para um resultado mais satisfatório do ensino da língua materna na escola - possibilita uma organização diferente dos conteúdos programáticos de Língua Portuguesa e, especificamente, de gramática, que serão organizados a partir das sequências textuais e não dos gêneros propriamente ditos.

A ênfase que se dá, hoje, ao trabalho com o texto na sala de aula é fundamental, mas não pode ser desenvolvido 
sem a investigação responsável das estruturas da língua que entram em sua composição. A gramática constitui, ela própria, uma estrutura cognitiva. Como tal, ela organiza o léxico, colocando-o em funcionamento nas interações sociais. Conhecer o seu funcionamento é condição para um uso mais consciente e, portanto, mais eficiente do arsenal linguístico que o falante tem a sua disposição.

\subsection{GÊNEROS TEXTUAIS}

Os gêneros textuais são o instrumento por meio do qual colocamos a língua em funcionamento nas interações sociais. São, portanto, textos concretos que circulam em sociedade e que cumprem funções sociais específicas; têm formato e composição relativamente estáveis, conteúdo, estilo, objetivo comunicacional e modo de veiculação característicos. São objetos culturais e existem em grande quantidade e diversidade, podendo variar de cultura para cultura.

A tirinha, por exemplo, é um gênero textual.
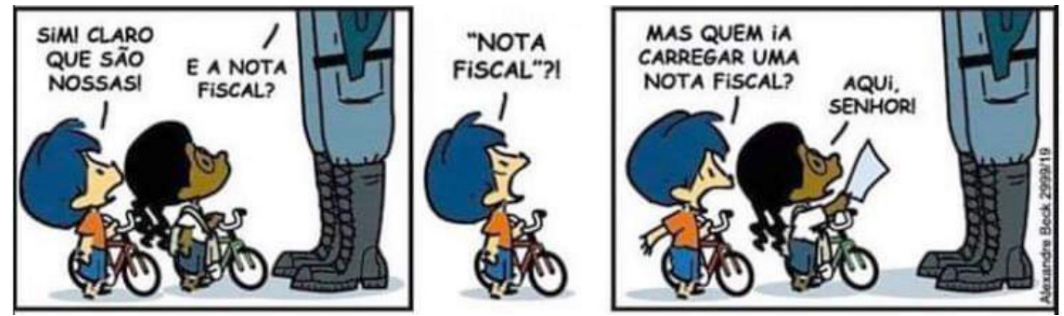

BECK, Alexandre. Armandinho. Disponível em: https://revistatrip.uol.com.br/trip/o-pai-doarmandinho-o-menino-de-cabelo-azul-que-reflete-sobre-arte-a-politica-e-direitos-humanos. Acesso em: 10 jan. 2021. 
Normalmente veiculada em jornais e revistas, a tirinha configura-se, em sua diagramação típica, como um texto composto por uns poucos quadrinhos - entre um e quatro, normalmente -, em que se combinam o verbal e o não verbal. Nela, apresenta-se a "fala" das personagens - enunciados curtos - distribuída em balões. O conteúdo tratado na tirinha é quase sempre uma crítica aos modos de comportamento social, político, aos valores, aos sentimentos. Em relação ao estilo, pode-se dizer que a tirinha traz a marca individual de seu autor, em seus traços e em sua linguagem, normalmente marcada pela informalidade.

Envolvidos em diversas práticas sociais em seu dia a dia, os falantes utilizam uma grande variedade de gêneros orais e escritos, lançando mão do que Koch (2006) chamou de competência metagenérica. Tal competência possibilita-nos interagir convenientemente, capacitando-nos para produzir e para compreender os gêneros textuais. A tirinha é um entre tantos outros gêneros, como o conto, o poema, a notícia, a entrevista, o relatório, a procuração, o bilhete, o e-mail, a palestra, o discurso político, a aula, a missa, etc.

Sendo objetos culturais, há gêneros característicos de outras culturas, desconhecidos em nossa sociedade, portanto. Assim como há gêneros comuns entre nós e 
desconhecidos de outros povos. Lembremo-nos do mangá japonês, recentemente descoberto pelos jovens ocidentais. Há, também, gêneros que estão deixando de ser usados, desaparecendo de nossa prática social - a carta pessoal - e outros que surgiram mais recentemente - o e-mail - e que ainda surgirão, motivados por necessidades comunicativas que o futuro trará.

Os textos socialmente considerados como representantes de determinado gênero têm características semelhantes, atribuídas a restrições genéricas: os gêneros têm identidade e nos condicionam a escolhas, quando de sua produção, que não podem ser livres nem aleatórias. Segundo Bakhtin (2003), eles limitam nossa ação na fala e na escrita, organizando-a, assim como a gramática organiza as formas linguísticas.

\subsection{SEQUÊNCIAS TEXTUAIS}

Segundo Jean Michel Adam (1992), as sequências textuais são organizações linguístico-formais que entram na configuração de um gênero para realizar objetivos discursivos por ele suscitados - como narrar, descrever, argumentar etc. Elas atendem a critérios basicamente linguísticos e são descritas por meio das estruturas gramaticais e dos elementos linguísticos característicos de 
sua constituição formal. Essas sequências são "esquemas" linguísticos básicos cuja função, conforme Bronckart (1999), é organizar linearmente seu conteúdo temático, exercendo papel fundamental na organização infraestrutural mais geral dos textos. Para Adam, os gêneros são considerados como componentes da interação social e as sequências, como organizações linguístico-formais em interação no interior de um gênero.

As sequências, ao contrário dos gêneros, são em número relativamente pequeno - em torno de seis - e não se configuram como um inventário aberto, como acontece com os gêneros. Embora sendo poucas, há divergências entre os tipos de sequências apresentadas pelos autores. Adam, por exemplo, propõe a existência das sequências narrativa, descritiva, argumentativa, explicativa e dialogal. Marcuschi (2002) trabalha com os tipos textuais (sequências) narrativa, descritiva, argumentativa, expositiva e injuntiva. Consideramos a necessidade de abarcar as duas descrições, tomando como base a proposta de Adam e acrescentando a sequência injuntiva sugerida por Marcuschi. Há, em cada uma delas, a nosso ver, especificidades que, se exploradas, auxiliarão no trabalho com a leitura e a escrita na sala 
de aula, considerando-se a construção do sentido do texto a partir da investigação do objetivo comunicativo de seu autor. Para os propósitos deste trabalho, entretanto, trataremos das sequências narrativa e argumentativa, com o objetivo de demonstrar a validade da proposta pedagógica que desenvolvemos.

\subsection{CARACTERIZAÇÃO DAS SEQUÊNCIAS NARRATIVA E ARGUMENTATIVA}

As sequências textuais diferem uma das outras no que diz respeito às características linguísticas que apresentam, uma vez que a iconicidade diagramática aponta um arranjo icônico diferente dos signos que compõem uma e outra. As consequências desse arranjo característico dos signos são o cumprimento de objetivos discursivos distintos pelo falante/ escritor e o reconhecimento da presença de sequências diferentes na composição de um mesmo gênero textual.

Normalmente, o texto é heterogêneo em relação às sequências que o compõem. Por isso a importância de se esclarecer que o que chamamos de sequência é, de fato, um segmento de texto, não um texto empírico. É necessário que isso seja observado quando do trabalho com a leitura e a escrita na escola, uma vez que essa heterogeneidade se refletirá no reconhecimento, pelo leitor, das escolhas das 
estruturas - gramática e léxico - feitas pelo autor do texto, atribuindo sentido a elas, e nas escolhas que o próprio aluno terá de fazer para compor seu texto.

A sequência narrativa é aquela que, como o próprio nome diz, narra um fato, um acontecimento, uma história. Nela estão envolvidos os atores da situação narrada, os próprios eventos e o narrador, responsável pelo relato dos fatos. Normalmente a ordem da narrativa segue a ordem do próprio evento objeto da narração, e esse arranjo icônico dos signos é uma das características que distinguem a sequência narrativa da sequência argumentativa, que se dispõe de forma distinta.

Partimos de Adam (1992), que caracteriza a sequência narrativa como composta por seis macroproposições: situação inicial, complicação, (re)ações, resolução, situação final e moral. A situação inicial e a situação final representam os momentos de equilíbrio da ação e têm uma base mais descritiva. A complicação, as (re)ações e a resolução é o que, de fato, caracteriza o esquema narrativo: um fato ocorre, quebrando o equilíbrio inicial e desencadeando (re)ações; essas (re)ações forçam uma resolução, que cria uma nova situação de equilíbrio. A moral, quando há, é uma reflexão acerca dos fatos narrados e é de responsabilidade do narrador. 
Aproximando essas noções dos objetivos de nosso trabalho, propomos que se observem as sequências em suas especificidades estruturais e funcionais. Para tanto, é preciso estabelecer um limite - até quando for possível entre cada uma delas.

Analisando-se os gêneros de base narrativa - contos, fábulas, romances, notícias, para citar alguns -, é possível reconhecer neles, em geral, a macroestrutura apresentada por Adam. Consideramos, entretanto, como sequência narrativa somente a complicação, as (re)ações e a resolução que deles fazem parte, uma vez que nelas é que encontramos as marcas linguísticas da narração em si. A situação inicial e a situação final, momentos chamados de equilíbrio, são de fato sequências descritivas, pois a primeira cria uma imagem do espaço onde a história se passará e das personagens que dela participarão, enquanto a segunda constrói uma outra imagem, que registrará a nova ordem das coisas após o desenrolar dos fatos relatados na sequência narrativa. A sequência descritiva é a menos autônoma e geralmente não é a que predomina nos textos de que faz parte. Ao contrário da narrativa, a sequência descritiva não apresenta uma ordem muito fixa. Em geral, consiste na apresentação de propriedades e características relacionadas ao elemento objeto da descrição. Já o que Adam 
chama de moral - quando existe explicitamente no texto configura-se como sequência argumentativa, pois é uma avaliação crítica do que se narrou, objetivando influenciar o leitor/ouvinte. É o que se procura planificar no quadro abaixo:

Quadro 1: Gênero de base narrativa planificado

\begin{tabular}{|c|c|c|c|c|c|}
\hline \multicolumn{5}{|c|}{ Gênero textual de base narrativa } \\
\hline $\begin{array}{c}\text { Situação } \\
\text { inicial }\end{array}$ & Complicação & (Re)ações & Resolução & $\begin{array}{c}\text { Situação } \\
\text { final }\end{array}$ & Moral \\
\hline $\begin{array}{c}\text { Sequência } \\
\text { descritiva }\end{array}$ & Sequência narrativa & $\begin{array}{c}\text { Sequência } \\
\text { descritiva }\end{array}$ & $\begin{array}{c}\text { Sequência } \\
\text { argumentativa }\end{array}$ \\
\hline
\end{tabular}

Fonte: ADAM, Jean Michael. Les textes: types et prototypes. Paris: Nathan, 1992. (Adaptado)

A sequência argumentativa, por sua vez, consiste, essencialmente, na contraposição de enunciados, que tem sua sustentação em operadores argumentativos, buscando defender um posicionamento. Esses operadores apõem um enunciado que está sendo construído a um já-dito (DUCROT, 1987). O esquema argumentativo se constrói, basicamente, pela apresentação de um argumento (dado explícito de sustentação de uma tese) e uma conclusão. Esse arranjo icônico da sequência pode sofrer variações de acordo com a estratégia argumentativa adotada pelo enunciador e com o tipo de raciocínio desenvolvido - dedutivo ou indutivo, por exemplo - para persuadir o interlocutor. A presença dos 
elementos básicos da argumentação é o que determina a sequência como argumentativa, não bastando para isso que se tenha a intenção, o objetivo argumentativo. A fábula é um gênero textual que exemplifica bem o que se diz aqui, pois constrói-se com estrutura narrativa (sequência narrativa), mas seu objetivo discursivo é, além de narrar, persuadir, modificar comportamentos - o que se dá no nível semântico (DUCROT, 1987), mas não no nível estrutural.

Muitos autores defendam a tese de que a argumentatividade é característica e objetivo de todos os textos. Adam (1992), entretanto, lembra que não se podem colocar no mesmo plano argumentatividade e o que denomina sequência argumentativa. A sequência é um mecanismo de textualização, um conjunto de proposições psicológicas que se estabilizaram como recurso composicional dos vários gêneros, sendo linguisticamente estável - o que possibilita sua determinação. A argumentatividade, por sua vez, prendese à natureza do discurso, ou seja, a sua orientação discursiva, que é de persuadir, pela apresentação de pontos de vista trazidos pelo locutor para o discurso. (DUTRA, 2007, p. 65)

Portanto, não se pode confundir a orientação argumentativa que se reconhece nos textos, com a existência de uma estrutura argumentativa prototípica, possibilitada pela presença da sequência argumentativa na composição dos gêneros. 
Encontramos, em Othon Moacyr Garcia (1985), dois planos-padrão para o que chama de argumentação formal e argumentação informal:

Quadro 2: Argumentação formal

\begin{tabular}{|c|c|c|c|}
\hline \multicolumn{4}{|c|}{ ARGUMENTAÇÃO FORMAL } \\
\hline $\begin{array}{c}\text { Proposição } \\
\text { (tese): } \\
\text { afirmativa } \\
\text { suficientemente } \\
\text { definida e } \\
\text { limitada; não } \\
\text { deve conter } \\
\text { em si mesma } \\
\text { nenhum } \\
\text { argumento. }\end{array}$ & $\begin{array}{c}\text { Análise da } \\
\text { proposição ou } \\
\text { tese: definição } \\
\text { do sentido da } \\
\text { proposição ou } \\
\text { de alguns de } \\
\text { seus termos, } \\
\text { a fim de } \\
\text { evitar mal- } \\
\text { entendidos. }\end{array}$ & $\begin{array}{c}\text { Formulação de } \\
\text { argumentos: } \\
\text { fatos, } \\
\text { exemplos, } \\
\text { dados } \\
\text { estatísticos, } \\
\text { testemunhos } \\
\text { etc. }\end{array}$ & Conclusão \\
\hline
\end{tabular}

Fonte: Elaborado pela autora a partir de GARCIA, Othon Moacyr. Comunicação em Prosa Moderna. 14. ed. Rio de Janeiro: Fundação Getúlio Vargas, 1988

Quadro 3: Argumentação informal

\begin{tabular}{|c|c|c|c|c|}
\hline \multicolumn{5}{|c|}{ ARGUMENTAÇÃO INFORMAL } \\
\hline $\begin{array}{c}\text { Citação } \\
\text { da tese } \\
\text { adversária }\end{array}$ & $\begin{array}{c}\text { Argumentos } \\
\text { da tese } \\
\text { adversária }\end{array}$ & $\begin{array}{c}\text { Introdução } \\
\text { da tese a ser } \\
\text { defendida }\end{array}$ & $\begin{array}{c}\text { Argumentos } \\
\text { da tese a ser } \\
\text { defendida }\end{array}$ & Conclusão \\
\hline
\end{tabular}

Fonte: Elaborado pela autora a partir de GARCIA, Othon Moacyr. Comunicação em Prosa Moderna. 14. ed. Rio de Janeiro: Fundação Getúlio Vargas, 1988

\subsection{BASE LINGUÍSTICA DAS SEQUÊNCIAS NARRATIVA E ARGUMENTATIVA}

Há aspectos linguístico-gramaticais que são característicos da constituição da sequência narrativa, assim como há outros que são mais determinantes na constituição da sequência argumentativa e de cada uma das demais sequências. 


\subsubsection{SEQUÊNCIA NARRATIVA}

Como se viu, a ordem de apresentação das macroproposições do texto narrativo (das narrativas lineares tradicionais) é normalmente fixa, obedecendo à linearidade temporal. Por isso essa sequência é considerada a mais apropriada para, a partir dela, por exemplo, se apresentar aos alunos a relação entre os tempos pretérito perfeito, pretérito imperfeito e pretérito mais-que-perfeito do indicativo, discutindo seu emprego e suas funções no texto. A coerência temporal é um aspecto a ser observado com muito cuidado, pois a manutenção da linha temporal é, normalmente, um ponto frágil na produção de texto dos alunos. Os tempos e modos verbais desempenham um papel importante na leitura (compreensão) e na escrita (produção) dos textos de uma forma geral, mas, principalmente, dos gêneros constituídos basicamente por sequências narrativas. Assim, é fundamental discutir com os alunos, observando o texto que está sendo analisado, se o autor constrói a linearidade temporal da narrativa - quais os elementos gramaticais que ele utiliza para isso e de que forma - ou se opta por romper essa linearidade, voltando ao passado ou projetando acontecimentos no futuro. É esse o momento de investir no trabalho com os tempos e modos, e na forma como eles se relacionam uns com os outros. 
O emprego dos artigos definido e indefinido também merece atenção especial quando do trabalho com gêneros de base narrativa. Conforme Kaufman (1995, p. 22), a apresentação das personagens ajusta-se à estratégia da definibilidade. As personagens são apresentadas, pela primeira vez no texto, por meio de um sintagma nominal introduzido por um artigo indefinido (ou outro elemento a ele equivalente). Quando essa personagem é novamente referida no decorrer do texto, o artigo indefinido é substituído pelo definido ou o termo por ele encabeçado é substituído integralmente por um nome, pronome, etc. Esses são aspectos da referenciação, um mecanismo coesivo extremamente importante para a constituição do enunciado. É preciso ir além do que diz a gramática normativa acerca do emprego dos artigos - e dos pronomes -, alertando o aluno para o papel que desempenham no texto, pois é nele que se materializa a linguagem e, portanto, é nele que se deve investigar seu funcionamento. Conforme Neves:

Na verdade, ao estudar-se o funcionamento da linguagem, o que está em questão são prioritariamente os processos, e é a compreensão deles que governa a compreensão dos arranjos dos itens que os expressam adequadamente. (NEVES, 2000, p. 64) 
O emprego de conectivos também é um aspecto muito importante na constituição do sentido do texto, uma vez que explicita, para o leitor, a intenção do autor no que diz respeito à construção das relações lógico-semânticas no texto observadas. As relações lógico-semânticas mais frequentes que se estabelecem entre os enunciados que formam a sequência narrativa são as de tempo e as de causa. É fundamental, então, que se investiguem os conectivos que explicitam tais relações nos textos que estão sendo lidos em sala de aula. Esses conectivos podem se afigurar como conjunções, locuções prepositivas, locuções adverbiais, marcadores discursivos, entre outros. Esse trabalho será de grande valia para a ampliação do repertório de que o aluno lança mão para construir tais relações nos textos que escreve.

Por último - mas não esgotando todas as possibilidades de exploração dos aspectos linguísticos constitutivos da sequência narrativa -, é preciso observar como o autor dos textos em análise constrói o ponto de vista da narrativa. $\mathrm{O}$ narrador é uma "entidade" criada pelo autor do texto para narrar os fatos que geram o enredo do texto lido. É a voz que guiará o leitor na construção do sentido do texto. Essa voz pode-se apresentar em primeira pessoa ou em terceira pessoa, e faz parte da coerência do texto a manutenção do 
ponto de vista adotado desde o início da narrativa. É mais uma oportunidade para mostrar aos alunos a função e o uso textual dos pronomes pessoais e demonstrativos, para que eles possam empregá-los com mais propriedade em seus próprios textos.

\subsubsection{SEQUÊNCIA ARGUMENTATIVA}

O texto constituído por sequências argumentativas, diferentemente do que ocorre com textos de base narrativa, não obedece a uma organização temporal. Ao contrário, o texto argumentativo se constitui a partir de um planejamento, buscando realizar uma estratégia argumentativa específica elaborada por seu autor. As estratégias argumentativas visam a convencer, persuadir, fazer aceitar, fazer crer, fazer mudar de opinião, levar a uma determinada ação. Dessa forma, é essa estratégia que ditará a organização das partes que irão compor o texto. Assim, os tempos verbais mais característicos de gêneros de base argumentativa são os do subsistema do presente, em sua correlação com o futuro.

Os elementos que compõem as sequências argumentativas podem organizar-se de forma distinta das apresentadas nos quadros 2 e 3, que são duas entre tantas estratégias argumentativas à disposição do autor de textos de base argumentativa. Dependendo 
da organização imposta aos elementos constituintes da sequência argumentativa, as relações lógico-semânticas entre suas partes serão umas e não outras. Esse é um aspecto fundamental para a construção da coerência do texto. Portanto, a articulação entre as suas partes, tornando explícita a intenção do autor por meio do emprego de conectivos e organizadores textuais que o encaminham a uma conclusão, é um dos aspectos linguísticos mais relevantes nesse tipo de sequência. Assim, é preciso explorar palavras e expressões que anunciam a posição do autor diante do que está sendo enunciado; que introduzem argumentos, estabelecendo relações lógicas entre as diferentes partes do enunciado (orações, períodos); que apresentam o fechamento, a conclusão do texto; que articulam o texto como um todo (grupos de períodos, parágrafos, partes maiores do texto).

Um outro aspecto linguístico de muita relevância aqui é a enunciação (quem fala no texto, como se apresenta). É importante que se avalie o efeito de sentido causado pela opção por uma ou por outra forma de enunciação. Sendo capaz de perceber o efeito diferenciado obtido quando do uso da primeira pessoa, da voz passiva, do sujeito indeterminado, da impessoalidade ou mesmo da terceira 
pessoa em lugar da primeira, o aluno poderá identificar, com mais facilidade, o objetivo do autor, desvendando-lhe a intenção.

\subsection{AS SEQUÊNCIAS NO INTERIOR DO GÊNERO}

Retomando a ideia de que as sequências textuais são organizações linguístico-formais em interação no interior dos gêneros, cabe esclarecer, mais uma vez, que um gênero pode ser considerado narrativo, por exemplo, mas apresentar outras sequências em sua constituição formal. O romance pode apresentar - e geralmente apresenta -, além de sequências narrativas, sequências descritivas, argumentativas, dialogais. O editorial de jornal, por sua vez, além da sequência argumentativa, pode apresentar outras, como a narrativa, a descritiva. Entretanto, os dois gêneros serão caracterizados como narrativo e argumentativo, respectivamente, por conta da predominância dessas sequências em sua constituição.

As especificidades linguístico-gramaticais existentes em cada sequência devem ser exploradas de forma planejada, a partir de gêneros que a apresentem em sua constituição, para que essas estruturas específicas possam ser reconhecidas nos textos analisados pelos alunos e utilizadas adequadamente quando da produção de textos. 
A ênfase no estudo das sequências deve-se dar em diferentes frentes. O aluno precisa reconhecer o papel discursivo da sequência (narrar, argumentar, descrever etc.) e sua contribuição para a constituição do gênero de que faz parte. Ele precisa, ainda, ser capaz de selecionar, entre as possibilidades que a língua oferece, e colocar em uso adequadamente, os elementos que realizam a função requerida pela sequência em pauta. É preciso, também, saber combinar as sequências e articulá-las para que, de sua combinação, resulte um texto coeso e coerente. Além disso, é preciso que o aluno registre seu texto, por meio da escrita, fazendo uso dos aspectos formais exigidos pela variedade de língua característica do gênero (ortografia, pontuação, concordância etc.). Esse último aspecto é comum a todas as sequências e deve ser tratado com a ênfase necessária, pois também dele depende a clareza do texto.

É nesse sentido que consideramos fundamental o trabalho com a gramática em sala de aula. Um trabalho com as estruturas da língua a serviço da construção de significados, tanto na compreensão quanto na produção dos textos. É nesse sentido, também, que, a nosso ver, o professor pode e deve se beneficiar das contribuições das perspectivas teóricas formalista e funcionalista, 
complementares que são, naquilo que uma e outra possam contribuir para o trabalho com a leitura e a produção de textos em sala de aula.

\section{CONSIDERAÇÕES FINAIS}

Com base na Linguística Funcional, consideramos a diferença estrutural verificada entre as sequências textuais, explicadas tais diferenças pelos objetivos discursivos distintos que apresentam. Consideramos, também, o próprio modo como os gêneros se diferenciam estruturalmente uns dos outros, como resultado da função social que são chamados a cumprir e da motivação para tais diferenças. É a expressão sendo motivada pelas funções que a língua é chamada a cumprir, uma das bases de sustentação do funcionalismo linguístico.

Os conceitos de sequência textual e de gênero textual, conforme aqui considerados, podem promover uma mudança relevante no trabalho com a leitura e com a escrita na escola, e, consequentemente, uma mudança no quadro desalentador que temos hoje: os alunos saem da escola, depois de, no mínimo, doze anos de escolarização, sem o domínio básico da leitura e da escrita, competências essenciais para a vida em sociedade.

A proposta aqui delineada permitirá que o professor construa um trabalho em que verdadeiramente se possam 
aliar gramática e texto. Permitirá que ele possa mostrar ao aluno a aplicabilidade dos conhecimentos gramaticais adquiridos aos textos que lê e aos textos que escreve.

O aluno, por sua vez, poderá perceber a relação íntima existente entre aspectos linguísticos e sequências textuais, transportando, automaticamente, os conhecimentos linguísticos adquiridos de um gênero para outro, desde que eles apresentem, em sua base linguístico-textual, a mesma sequência.

Nosso objetivo, enfim, é a mudança de perspectiva nas aulas de Língua Portuguesa, buscando um resultado mais satisfatório no que diz respeito à leitura e à produção de textos de nossos alunos, que, cada vez mais distantes da leitura e da escrita proficientes, tornam-se cidadãos acríticos e distantes das diversas instâncias decisórias da sociedade a que pertencem.

\section{REFERÊNCIAS}

ADAM, Jean Michael. Les textes: types et prototypes. Paris: Nathan, 1992. BAKHTIN, Mikhail. Os gêneros do discurso. In: BAKHTIN, Mikhail. Estética da criação verbal. 4. ed. São Paulo: Martins Fontes, 2003.

BRONCKART, Jean-Paul. Atividade de linguagem, textos e discursos: por um interacionismo sócio-discursivo. São Paulo: Educ, 1999.

DUCROT, Oswald. O dizer e o dito. Campinas: Pontes, 1987.

DUTRA, Vania Lúcia Rodrigues. Relações conjuntivas causais no texto argumentativo. Orientadora: Darcilia Simões. 2007. Tese (Doutorado em 
Língua Portuguesa) - Instituto de Letras, Universidade do Estado do Rio de Janeiro. Rio de Janeiro. 2007.

FALCÃO, Adriana. Pequeno dicionário de palavras ao vento. São Paulo: Salamandra, 2013.

GARCIA, Othon Moacyr. Comunicação em Prosa Moderna. 14. ed. Rio de Janeiro: Fundação Getúlio Vargas, 1988.

HALLIDAY, Michael Alexander Kirkwood. Language as social semiotic: the social interpretation of language and meaning. London: Edward Arnold, 1979.

HALLIDAY, Michael Alexander Kirkwood. An introduction to functional grammar. 2. ed. London: Edward Arnold, 1994.

KAUFMAN, Ana María; RODRIGUÉZ, Maria Helena. Escola, leitura e produção de textos. Porto alegre: Artes médicas, 1995.

$\mathrm{KOCH}$, Ingedore; ELIAS, Vanda Maria. Ler e compreender os sentidos dos textos. São Paulo: Contexto, 2006.

MARCUSCHI, Luiz Antônio. Gêneros Textuais: definição e funcionalidade. In: DIONISIO, Angela; MACHADO, Anna Rachel; BEZERRA, Maria Auxiliadora (Orgs.). Gêneros Textuais e Ensino. Rio de Janeiro: Lucerna, 2002.

NEVES, Maria Helena de Moura. A Gramática Funcional. São Paulo: Martins Fontes, 1997.

NEVES, Maria Helena de Moura. A gramática: conhecimento e ensino. In: AZEREDO, José Carlos de (Org.). Língua Portuguesa em debate. Petrópolis: Vozes, 2000.

NEVES, Maria Helena de Moura. Texto e gramática. São Paulo: Contexto, 2007.

OLIVEIRA, Roberta Pires de. Formalismos na linguística: uma reflexão crítica. In: MUSSALIM, Fernanda; BENTES, Anna Christina (Orgs.). Introdução à linguística - fundamentos epistemológicos. Vol. 3. 2. ed. São Paulo: Cortez Editora, 2004, p. 219-250.

PEZZATI, Erotilde Goreti. O funcionalismo em linguística. In: MUSSALIM, Fernanda; BENTES, Anna Christina (Orgs.). Introdução à linguística - 
fundamentos epistemológicos. Vol. 3. 2. ed. São Paulo: Cortez Editora, 2004, p. 165-218.

SIMÕES, Darcilia Marindir Pinto. Iconicidade verbal: Teoria e Prática. Rio de Janeiro: Dialogarts, 2009.

Vania. L. R. Dutra é professora Associada do Instituto de Letras da Universidade do Estado do Rio de Janeiro. Professora Titular da Universidade Federal Fluminense, Coluni-UFF. Doutora em Língua Portuguesa pela Universidade do Estado do Rio de Janeiro, com a Tese "Relações conjuntivas causais no texto argumentativo" (2007), orientada pela Profa. Drª. Darcilia Simões. Mestre em Língua Portuguesa pela Universidade Federal Fluminense. Professora no Programa de Pós-Graduação em Letras, na especialidade Língua Portuguesa, professora no Curso de Especialização e na Graduação do Instituto de Letras da UERJ. Membro do grupo de pesquisa SELEPROT: Semiótica, Leitura e Produção de Texto, coordenado pela Profa. Drá. Darcilia Simões, e do GT "Linguística Sistêmico-Funcional" da Anpoll. Desenvolve pesquisas na área da Linguística Sistêmico-Funcional, em interface com alguns aspectos da Semiótica, principalmente da Iconicidade Verbal, com especial ênfase nos seguintes temas: ensino de Língua Portuguesa - gramática, leitura e produção de texto. Autora de vários capítulos de livros e artigos em periódicos e em anais de eventos, sobre Linguística Sistêmico-Funcional e suas contribuições para o ensino de língua materna, alguns deles em coautoria com a Profa. Dra. Darcilia Simões, alguns outros em publicações viabilizadas por ela, por meio das Publicações Dialogarts, projeto concebido e coordenado pela Professora ao longo de mais de duas décadas. 